\title{
Tekstil İşletmelerinde İnovasyon Uygulamalarına Yönelik Bir Araştırma: İstanbul Sanayi Odası Örneği ${ }^{*}$
}

Öz

Günümüz küresel rekabet şartlarında tekstil işletmelerinin rekabetçi konuma ulaşmak ve bu konumlarını sürdürmek için kullanabilecekleri en önemli araçlardan birisi inovasyondur. Bu çalışmada, Türkiye'deki tekstil işletmelerinin inovasyon faaliyetlerinin incelenmesi amaçlanmıştır. Bu amaçla 2017 yılında İstanbul Sanayi Odası (ISO) 'nın 1. ve 2. 500 büyük işletme sıralamasında yer almayı başarmış tekstil işletmelerinin resmi web siteleri incelenmiştir. İnceleme sonucunda tekstil işletmelerinin; ürün, süreç, pazarlama ve organizasyon kapsamındainovasyon faaliyetleri gerçekleştirdikleri tespit edilmiştir. Ancak işletmelerin ürün inovasyonu dışındaki diğer inovasyon türlerinde dikkate değer bir inovasyon faaliyetine rastlanmamıştır. Sonuç olarak tekstil işletmelerinin pazarlama, süreç ve organizasyonel inovasyon türlerine daha fazla yönelmeleri gerektiği kanaatine varılmıştır.
\end{abstract}

Anahtar Kelimeler: İnovasyon, inovasyon türleri, tekstil işletmeleri.

\section{A Research of Innovation Applications in Textile Enterprises: The Case of Istanbul Chamber of Industry}

\begin{abstract}
In today's global competition conditions, innovation is one of the most important tools that textile enterprises can use to reach and maintain a competitive position. The aim of this study is to examine innovation practices carried out by Turkish textile enterprises. For this purpose, in 2017, the official web sites of the textile enterprises that managed to take place in the 1st and 2nd 500 largest enterprises of Istanbul Chamber of Industry (ISO) were examined. As a result of the investigation, it was determined that textile enterprises carried out innovation activities in terms of product, process, marketing and organization. However, there is no significant innovation activity in other types of innovation other than product innovation. As a result, it was concluded that textile enterprises should be more oriented towards marketing, process and organizational innovation types.
\end{abstract}

Keywords: Innovation, types of innovation, textile enterprises.

\footnotetext{
* Bu çalışma, 7-8 Aralık 2018 tarihlerinde Antalya`da gerçekleştirilen 2. Uluslararası Türk Dünyası Eğitim Bilimleri ve Sosyal Bilimler Kongresi nde sunulan "Tektil İşletmelerinde İnovasyon Uygulamaları: Türkiye Örneği” başlıklı bildirinin güncellenmiş ve genişletilmiş halidir.

** Dr. Öğr. Üyesi, Bayburt Üniversitesi, yesmer@bayburt.edu.tr, Orcid No: 0000-0003-3691-1730.

*** Dr. Öğr. Üyesi, Marmara Üniversitesi, aozbek@marmara.edu.tr, Orcid No: 0000-0001-5015-8082.

**** Bayburt Üniversitesi, alanasif@hotmail.com, Orcid No: 0000-0002-6947-404X
} 


\section{Giriş}

Tekstil ürünleri (lif, iplik, kumaş vb.) üretimi günümüzdeki halini alıncaya kadar önemli değişimler geçirmiştir. İlk tekstil ürünleri üretimi neredeyse tamamıyla insan emeğine dayalı iken, 18. yy da sanayi devrimiyle birlikte ilk dokuma makinesi tekstil ürünleri üretiminde kullanılmaya başlanmıştır. Bu durum tekstil üretiminde makineleşmenin başlamasına neden olmuştur. Ayrıca 19. yüzyılın ortalarına kadar tekstil ürünlerinin hammaddelerini doğal malzemeler (pamuk, keten, yün vb.) oluştururken, bu tarihlerde sentetik malzemeler (petrol, selüloz vb. esaslı) de üretimde kullanılmaya başlanmıştır. Sentetik liflerin üretilmesiyle birlikte de teknik ve akıllı tekstillerin üretimi mümkün hale gelmiştir (Küçükkalay, 1997; Mecit vd., 2007; Taylan ve Atlihan, 2018).

Tekstil ürünleri üretim teknolojisindeki bu gelişmeler, küreselleşme ve bilgi-iletişim teknolojilerinin gelişimi, yerel düzeyde yaşanmakta olan rekabeti, küresel boyuta dönüştürmüştür (Choi vd., 2005; Şendoğdu ve Öztürk, 2013; Çakın ve Özdemir, 2018). Tekstil işletmeleri arasında yaşanmakta olan küresel rekabet günümüz müşterilerinin istek ve ihtiyaçlarının da sürekli olarak değişmesine neden olmaktadır (Çakın ve Özdemir, 2018). Öyle ki lider konumdaki bir işletme tüketicinin beklentilerine uygun ürün ve hizmetler geliştiremediğinde rekabet avantajını kaybetmektedir (İlter vd., 2016). Bu koşullar altında işletmelerin rekabet edebilmeleri; yeni ürün ve hizmetler üretmek, ürün yaşam döngülerini kısaltmak, maliyetleri düşürmek, yeni teknoloji ve pazarlama imkanları geliştirerek müşteri taleplerini en iyi şekilde karşılamak, daha verimli ve etkin olabilmek ve bu etkinlik ve verimliliklerini devam ettirebilmek ile mümkün olmaktadır (Bayhan, 2004; Choi vd., 2005; Yeşil vd., 2010; Altuntaş ve Dereli, 2016; Küsters vd., 2017; Şaylan ve Esmer, 2017; Çakın ve Özdemir, 2018).

Günümüzde tekstil işletmelerinin, üretim süreçlerini geliştirerek, işletmeleri katma değer sağlayan yeni ürün (mal ya da hizmetler) üreterek rekabet edebilir hale dönüşmesini sağlayacak en önemli faktör ise inovasyondur (Dornier, 2015). Ancak yeni bir ürün değer oluşturduğu takdirde rekabet üstünlüğüne katkı sağlayabilmektedir (Kaynak ve Demir, 2015). Bu bağlamda "değer oluşturma" sürecinden geçen "yenilik" in ortaya çıkması inovasyondur (Yorgancılar, 2011). Bu nedenle inovasyon; yeni fikirler ve üretim yöntemleri geliştirmek, yeni ürünler üretmek, üretilmekte olan ürünü kısmi olarak değiştirmek ve/veya başka alana uyarlamak, yeni pazarlar oluşturmak, yeni hammadde veya yarı mamul sağlamak için kaynaklar geliştirmek, yeni organizasyonlar oluşturmak vb. faaliyetleri içermektedir (Akın ve Reyhanoğlu, 2014; Işık ve Kılınç, 2016).

Günümüzde tekstil işletmeleri; insanları korumak, sağlık koşullarını ve yaşam kalitesini iyileştirmek, memnuniyetlerini arttırmak amacıyla çeşitli inovasyon faaliyetleri yürütmektedir (Barburski vd., 2016). Bu faaliyetler sonucunda akıllı tekstil ve teknik tekstiller üretilmeye başlanmıştır. "Akıllı tekstiller, normal tekstil ürünlerinin doğal atmosfer şartlarından koruma ve süsleme özelliklerine ilave olarak herhangi bir etkiyi (1şık, 1s1, basınç, elektromanyetik dalgalar, ses ve ses ötesi dalgalar, hareket vb.) veya etki değişikliğini algılama ve buna bir tepki verme özelliğine sahip olan tekstil ürünleridir" (Coşkun ve Oğulata, 2008). Günümüzde insanların pek çok sorununu farklı şekillerde çözmek amacıyla akıllı tekstil üreten farklı sektörler ortaya çıkmaktadır (Paret ve Crégo, 2019).

Teknik tekstiller ise estetik veya dekoratif özelliklerinden ziyade teknik ve performans özellikleri için üretilen tekstil malzemeleri olup kendi aralarında; Tarımtek, İnşaattek, Giysitek, Geotek, Evtek, Endüstritek, Tiptek, Transporttek, Pakettek, Korumatek, Sportek ve Ekotek olarak çeşitli alanlara ayrılmaktadır (Berkalp, 2008). İnovasyonun tekstilde uygulanmasıyla, 
fonksiyonel tekstiller, dokusuz kumaşlar gibi çeşitli işlevlere hizmet eden teknik tekstil malzemelerinin geliştirilmesi ve üretilmesi sağlanmaktadır (Dornier, 2015).

Tekstil endüstrisinde meydana gelen yukarıda anlatılmakta olan inovasyona dayalı teknolojik gelişmeler, emek yoğun üretime dayalı olan sektörü teknoloji ve sermaye yoğun bir sektöre dönüştürmektedir (Çütçü ve Çelik, 2016). Ancak Kuştepeli ve Gülcan (2010) tarafindan, İstanbul ve Denizli ilinde bulunan tekstil kümelerinin yenilik kapasitelerine dair yapılan çalışmada işletme sahip/yöneticilerine uluslararası, mili ve bölgesel seviyede yenilikçilik politikalarından yararlanıp yararlanmadıkları sorulmuş ve işletme sahip/yöneticilerin hiçbirinin olumlu cevap vermedikleri tespit edilmiştir. Aynı çalışmada bu olumsuzluğun; inovasyon destekleme araçlarının karmaşıklığı, bilgi eksikliği, işletme ihtiyacina cevap vermeyen destekler ve zaman probleminden kaynaklandığ ortaya konulmuştur. OECD Oslo Kılavuzu (2005), başlıca 4 temel inovasyon türüne odaklanmaktadır. Bunlar; ürün inovasyonu, süreç inovasyonu, pazarlama inovasyonu ve organizasyonel inovasyonlardır. Ürün inovasyonu, ürünün mevcut özellikleri veya öngörülen kullanımına göre yeni ya da önemli derecede iyileştirilmiş ürün üretilmesi veya mevcut üründe değişiklik, farklılık, yenilik yapılarak pazara sunulmasıdır (Habikoğlu, 2015; Savaş, 2015; Çetin ve Gedik, 2017). Ürün inovasyonu, yeni bilgi veya teknolojilerden yararlanılarak oluşturulabileceği gibi mevcut bilgi ve teknolojilerin yeni alanlarda kullanılması ya da bunların bir birleşimi şeklinde de olabilmektedir (Kıliç ve Keklik, 2012). İnovasyon sonucunda oluşan ürünün teknik özelliklerinde, bileşenlerinde ve malzemelerinde, kullanıcıya kolaylığında ve diğer işlevsel özelliklerinde önemli derecede iyileştirmeler ön plana çıkar (Çetin ve Gedik, 2017). Ürün inovasyonu işletmelerin; ürün yaşam sürecinin kısalmasına, talep belirsizliği ve teknolojik çalkantı gibi birçok rekabet baskısıyla başa çıkmasına yardımcı olabilmektedir (Savaş, 2015). İşletmelerin üretim sürecince inovatif teknolojileri kullanmalarıla da; üretim aşamaları kısalarak hem zaman kaybı ortadan kalkmakta hem de gereksiz harcamaların önüne geçilmektedir (Yılmaz Aykul, 2018). Ürün inovasyonunun daha iyi işletme performansına yol açarak işletme verimliliğini artırmaktadır (Wadho ve Chaudhry, 2018). İşletmeler özellikle pazar pozisyonlarını korumak ve geliştirmek için ürün inovasyon yeteneklerini geliştirmeye çalışmaktadırlar. Bu nedenle Ar-Ge/uzman insan sermayesine yatırım yapmaktadırlar (Herstad, 2018). Nefes alabilir kumaşların giyim eşyalarında kullanımı, iki taraflı giyilebilen ürünlerin üretimi, mutfakta kullanılan mikrofiber kumaşlar ve fonksiyonel/akıllı tekstiller gibi diğer teknik tekstiller, ürün inovasyonuna örnek olarak gösterilebilir (Kıllç ve Keklik, 2012). Ürün inovasyonunun 3 türü bulunmaktadır: Toplam; yeni ürün ve hizmeti yeni tür müşterilere sunma, yayılmacı; var olan mal ve hizmetleri daha önce olduğu gibi aynı kullanıcıya sunma, evrimci; aynı tür işletmelere yeni ürün ve hizmet sunmadır (Gonzalez vd., 2013).

Süreç inovasyonu, yeni ya da önemli derecede iyileştirilmiş; üretim, dağıtım ve/veya teslimat yönteminin geliştirilmesidir (Gürcüm ve Bulat, 2016; Çetin ve Gedik, 2017). Süreç inovasyonuyla; teknoloji, teçhizat, araç ve bilgi kullanılarak, mevcut ürünlerin daha hızlı, daha kaliteli ve daha az maliyetle üretilmesi sağlanır (Elçi ve Karataylı, 2008). Süreç inovasyonları işletme performansını (maliyetleri azaltarak, vb.) önemli ölçüde etkilemektedir (Habikoğlu, 2015). Tekstil sektörü, üzerindeki fiyat baskısı nedeni ile uzun süredir makine parkurlarının modernizasyonu, yeniden yapılanması, esnek üretim sistemlerinin adapte edilmesi gibi süreç inovasyonu faaliyetlerine önem vermektedir (Kardağl1, 2010; Rosli ve Sidek, 2013).

Pazarlama inovasyonu ürünün; tasarım, yerleștirme, tutundurma, fiyatlandırma, tasarım, paketleme, fiyatlandırma gibi faaliyetlerinin birinde veya birçoğunda önemli değişiklikler yapılarak yeni bir pazarlama yönteminin uygulanmasıdır. Pazarlama inovasyonunun amacı, müşteri istek ve ihtiyaçlarına cevap verecek farklı veya yeni ürünler tasarlamak, yeni pazarlar bulmak ve var olan ürünü pazarda yeni bir şekilde konumlandırmaktır. Böylece ürün satış 
miktarını artırmaktır (Elçi ve Karataylı, 2008; Savaş, 2015; Çetin ve Gedik, 2017; Yılmaz Aykul, 2018).

Organizasyonel inovasyon ise genel anlamda, işletmenin ticari uygulamalarında, işyeri organizasyonunda, işyeri dışındaki ilişkilerinde etkin ve yeni yöntemlerin geliştirilmesi ve uygulanmasıdır (Elçi ve Karataylı, 2008; Çetin ve Gedik, 2017; Yılmaz Aykul, 2018). Bir işletmenin rekabet avantaj elde edebilmesi ve bunu koruyabilmesi için çalışma yöntemlerini geliştirmesi, farklılaştırması ve yenilemesi organizasyonel inovasyon olarak adlandırılmaktadır (Savaş, 2015). Organizasyonel inovasyonlar, yönetim ve işlem maliyetlerini düşürmek, işyeri memnuniyetini dolayısıyla işgücü verimliliğini iyileştirmek, ticari olmayan varlıklara erişim sağlamak ve demirbaş maliyetlerini düşürmek suretiyle işletme performansını artırmaktadır (Çetin ve Gedik, 2017).

\section{Yöntem}

Bu araştırmanın problemi; “Türk tekstil işletmelerinin inovasyon faaliyetleri var mıdır? ve Eğer inovasyon faaliyetleri varsa hangi tür inovasyon faaliyetleri bulunmaktadır?" şeklinde ifade edilebilir. Araştırmanın amacı ise Türk tekstil İşletmelerinin inovasyon faaliyetlerini incelemektir. İncelenen inovasyonları türlerine göre sınıflandırmak ve işletmelerin güçlü ve zayıf olduğu inovasyon türlerini tespit etmektir. Sonuç olarak Türk Tekstil işletmelerinin inovasyon türlerine göre durumlarını ortaya koyarak bu konuda yapılacak çalışmalar için akademisyenlere ve işletme yöneticilerine bilgi sağlamaktır.

Türk tekstil işletmeleri, genellikle KOBİ niteliğine sahip, ülkenin dört bir tarafına yayılmış ve yeterince kurumsallaşmamış işletmelerdir (TID, 2014; Şencan, vd., 2015; Koçoğlu ve Sarıtaş, 2016). Bu nedenle araştırmanın örneklemi olarak; ulaşılabilir olup ve daha fazla kurumsallaşmış olmaları nedeniyle bilgi elde etmenin daha hızlı ve kolay olduğu 2017 yılında, İstanbul Sanayi Odası (İSO)'nın 1. ve 2. 500 büyük işletme sıralamasında yer almış tekstil işletmeleri seçilmiştir. 2017 yılında ilgili sıralamaya girmeyi başarmış sadece 40 tekstil işletmesi bulunmaktadır. Çalışmada araştırmanın ana kütlesini oluşturan 40 tekstil işletmesinin tamamına ait inovasyon bilgileri işletmelerin resmi web sitelerinin incelenmesiyle elde edilmiştir. İşletmelerin inovasyon faaliyetleri hakkında bilgi edinmek amacıyla işletme yöneticileriyle telefon ve e-posta vasıtasıyla iletişime geçilmiş ancak işletmelerin yönlendirmesi sonucunda asıl bilgi kaynağ olarak işletmelerin resmi internet siteleri kullanılmıştır. Bunun nedeni ise günümüzde işletmelerin inovasyon faaliyetlerini prestij sağlama nedeniyle resmi internet sitelerinde yayınlamalarından kaynaklanmaktadır. $\mathrm{Bu}$ bağlamda araştırmada Kesitsel Tarama Yöntemi kullanılması uygun görülmüştür (Metin, 2014). Diğer yandan araştırmada tekstil işletmelerinin tüm inovasyon uygulamalarına ulaşılamaması araştırmanın önemli bir kısıtı olarak görülmektedir. Bu bağlamda teksil işletmelerinin stratejik gördüğü, paylaşılmasını istemediği ya da herhangi bir nedenle websitelerine koymadığ

\section{Bulgular}

Araştırmanın örneklemini oluşturan 40 tekstil işletmesinin resmi web siteleri incelenmiştir. İncelenen 40 işletme web sitesinden sadece 20 tekstil işletmesinin inovasyon faaliyetlerinde bulunduğu tespit edilmiştir. Bu 20 işletmeye ait 96 inovasyon uygulamasına ulaşılabilmiştir. $\mathrm{Bu}$ inovasyonlara yönelik detaylı bilgiler Tablo 1` de verilmiştir. Bu doğrultuda çalışmanın alt amaçları aşağıdaki gibi özetlenebilir: 
Tablo 1: Türk Tekstil İşletmelerinin İnovasyon Uygulamaları ve İnovasyon Türleri

\begin{tabular}{|c|c|}
\hline \multicolumn{2}{|c|}{ Sanko Tekstil İşletmeleri (Sanko Tekstil İşletmeleri, 2018); (Haber7, 2018); (Haberler, 2018); (ISKO, 2018) } \\
\hline İnovasyon Uygulamaları & İnovasyon Türü \\
\hline ISKO Future Face örme görünümlü ilk dokuma kumaş & Ürün \\
\hline \begin{tabular}{|l|l} 
ISKO Pop streç sürüm ile vücut kıvrımları için elastikiyet veren denim \\
\end{tabular} & Ürün \\
\hline $\begin{array}{l}\text { ISKO Pj Soft ekstra yumuşaklık ve hafiflik için pijamaların } 24 \text { saatlik rahatlığını sunan pürüzsüz } \\
\text { ve esnek denim }\end{array}$ & Ürün \\
\hline ISKO Scratch el yapımı eski giysilerden esinlenen bu radikal konsept ilk üç boyutlu denim & Ürün \\
\hline ISKO Stay Black doymuş siyah rengini yıkanmadan tutmasına izin veren denim & Ürün \\
\hline ISKO Jool yün atkı dokuma teknolojisine sahip denim & Ürün \\
\hline ISKO Jeather denim ile deriyi buluşturan, hakiki bir deri görünümü ve hissi sağlayan bir kumaş & Ürün \\
\hline $\begin{array}{l}\text { ISKO Athleisure spor kıyafetlerin lüks günlük kıyafetlerle birleştirilmesi olarak bilinen moda } \\
\text { akımının öncüsü }\end{array}$ & Pazarlama \\
\hline \begin{tabular}{|l|l} 
Jeggings markası kadın giyiminde yüksek elastikiyete sahip olan ve süper ince denim \\
\end{tabular} & Ürün \\
\hline ISKO Reform teknolojisi olağanüstü kumaş geri kazanımı & Ürün \\
\hline $\begin{array}{l}\text { ISKO Cottonized tamamen pamuksuz olarak üretilen, benzersiz bir parlaklık ve yumuşaklığı sunan } \\
\text { kumaş }\end{array}$ & Ürün \\
\hline \begin{tabular}{|l|l} 
Mavi ışık altında kumaş kontrolü yapılarak apraj probleminin kontrol çözümü \\
\end{tabular} & Ürün \\
\hline \multicolumn{2}{|l|}{ Gülsan Sentetik Dokuma (Gülsan Holding, 2018) } \\
\hline İnovasyon Uygulamaları & İnovasyon Türü \\
\hline $\begin{array}{l}\text { Türkiye' de ilkler; ilk tubular torba üretimi, ilk tubular file torba üretimi, ilk tubular şeffaf torba } \\
\text { üretimi, ilk lamineli kömür torbası, ilk BB alçı torbası, ilk BB çimento torbası, ilk sergilik takviyeli } \\
\text { kumaş üretimi, ilk sonsuz elyaftan halı ipliği üretimi, ilk tarım koruma örtüsü, ilk BB blok bottom } \\
\text { torba üretimi, ilk hijyenik amaçlı Spunbond üretimi, ilk hijyen amaçlı film üretimi }\end{array}$ & Ürün \\
\hline Dünya’ da ilkler; ilk BB torba üretimi, ilk PP BB alçı - çimento torbası üretimi & Ürün \\
\hline \multicolumn{2}{|l|}{ Kipaş Mensucat İşletmeleri (Kipaş Mensucat, 2018); (Texotex, 2018) } \\
\hline \begin{tabular}{|c|c|} 
İnovasyon Uygulamaları & \\
\end{tabular} & İnovasyon Türü \\
\hline $\begin{array}{l}\text { Tekstil kurutma sistemleri, } 1 \text { sı geri kazanımı ve soğutma suyunun boyahanelerde proses suyu olarak } \\
\text { kullanımı }\end{array}$ & Ürün \\
\hline Kurşungeçirmez, kızılötesi 1şınlarla görülmeyen, yanmaz, su geçirmez özellikli kumaş üretimi & Ürün \\
\hline \multicolumn{2}{|l|}{ Merinos Halı Sanayi (Merinos, 2018); (Haberalanya, 2018) } \\
\hline \begin{tabular}{|c|} 
İnovasyon Uygulamaları \\
\end{tabular} & İnovasyon Türü \\
\hline $\begin{array}{l}\text { Fabrikalarda kullanılan kompresör ve elektrik motorlarının verimliliğinin artırılması projesi ile } \\
\text { enerji tasarrufu }\end{array}$ & Ürün \\
\hline \multicolumn{2}{|l|}{ Kordsa Teknik Tekstil (Kordsaglobal, 2018); (Kordsa, 2018) } \\
\hline İnovasyon Uygulamaları & İnovasyon Türü \\
\hline \begin{tabular}{|l|} 
KraTos Makro ve KraTos Mikro Sentetik Fiber Donatıları ile Beton Güçlendirme Uygulamaları ile \\
endüstriyel zeminler, beton yollar, ray altı betonlar ve havalimanları gibi projede güçlendirme \\
teknolojisi olarak, betonun tokluğunu arttırma, sinyal sistemlerini manyetik akımlara karşı koruma \\
ve bu teknoloji sayesinde proje, işçilik ve imalat maliyetinde $\% 30$ civarı zaman tasarrufu sağlama
\end{tabular} & Ürün \\
\hline \begin{tabular}{|l|} 
Geliştirilen yeni reçine teknolojisi ile 9 dakika olan kürlenme süresinin 3 dakikaya indirilmesi ve \\
üretilen kompozit malzemenin yüzey kalitesinin iyileştirilmesi
\end{tabular} & Süreç \\
\hline \begin{tabular}{|l|} 
Yeşil renkli kord bezi ile endüstriyel tasarım tescilinin alınması \\
\end{tabular} & Ürün \\
\hline
\end{tabular}


Tablo 1 (Devamı): Türk Tekstil İşletmelerinin İnovasyon Uygulamaları ve İnovasyon Türleri

\begin{tabular}{|c|c|}
\hline \multicolumn{2}{|l|}{ Zorluteks Tekstil (Zorlu Tekstil, 2018) } \\
\hline \begin{tabular}{|l|} 
İnovasyon Uygulamaları \\
\end{tabular} & İnovasyon Türü \\
\hline $\begin{array}{l}\text { Serin tutan pike, kendini temizleyen kumaş ve stor perde, gençlere yönelik led 1şıklı perde, içerik } \\
\text { üreten QR kodlu nevresim gibi çok sayıda akıllı tekstil ürünü }\end{array}$ & Ürün \\
\hline \multicolumn{2}{|l|}{ Boyteks Tekstil (Boyteks, 2018) } \\
\hline İnovasyon Uygulamaları & İnovasyon Türü \\
\hline $\begin{array}{l}\text { Q-Dry\&Soft teknolojisi ile polyester kumaşlar hem yumuşak bir tuşe hem de mükemmel bir } \\
\text { hidrofilite kazanır }\end{array}$ & Ürün \\
\hline $\begin{array}{l}\text { Quantech Sleep teknolojisi uyku sırasında, gün boyu kaybettiğiniz enerjiyi geri kazandırarak yeni } \\
\text { güne dinlenmiş ve enerjik olarak uyanmaya yardımcı olur }\end{array}$ & Ürün \\
\hline $\begin{array}{l}\text { Triple Fresh uyku dünyasında bir ilk olan ortamının havasını temizleyerek uyku kalitesini artıran } \\
\text { yepyeni bir teknoloji sunmaktadır }\end{array}$ & Ürün \\
\hline $\begin{array}{l}\text { Biocare kumaşlar, uyku sırasında elektromanyetik dalgaların vücutla temasını } \% 98,5 \text { oranında } \\
\text { engelleyerek manyetik bariyer görevi üstlenir }\end{array}$ & Ürün \\
\hline $\begin{array}{l}\text { Olivoil Mikrokapsül teknolojisi sayesinde zeytinyağının tüm gençleştirici etkilerini kazanarak } \\
\text { uyku sırasında cildin nem dengesinin sağlanmasına yardımcı olunması }\end{array}$ & Ürün \\
\hline $\begin{array}{l}\text { Ametist Yatak Kumaşı Teknolojisi, kullanıcısının uyku konforunu yükselten ve bu yenilikçi } \\
\text { teknoloji, uykuya dalma süresini kısaltarak sağlıklı bir uyku ortamı sunması }\end{array}$ & Ürün \\
\hline $\begin{array}{l}\text { Mineraller ve Biorytmic Sleep yatak kumaşı minerallerin belirli bir geometrik yapıda bir araya } \\
\text { getirilmesi ile elde edilmesi }\end{array}$ & Ürün \\
\hline $\begin{array}{l}\text { Kızılötesi Terapi adı verilen Medicycle teknolojisi sayesinde, kızılötesi teknolojisi ve yayılan } \\
\text { radyasyon etkisi kontrol edilerek vücuttaki mineral, beslenme ve oksijenin iletilmesine yardımcı } \\
\text { olup rahat ve konforlu bir uyku ortamı sunulması }\end{array}$ & Ürün \\
\hline $\begin{array}{l}\begin{array}{l}\text { Cooler teknolojisi özel iplikleri sayesinde uyku sırasında vücuttaki yüksek 1sıyı emerek vücudun } \\
\text { serin kalmasına yardımcı olunması ve uyku sırasında terlemeyi önleyip vücut nemini dengeleyerek } \\
\text { uyku kalitesinin maksimuma taşınması }\end{array} \\
\end{array}$ & Ürün \\
\hline \multicolumn{2}{|l|}{\begin{tabular}{|l|l} 
Menderes Tekstil (Menderes, 2018); (Menderes Tekstil, 2017) \\
\end{tabular}} \\
\hline İnovasyon Uygulamaları & İnovasyon Türü \\
\hline $\begin{array}{l}\text { Single-pass dijital baskı teknolojisiyle üretim hızı ve ürün kalitesi ileri seviyeye taşınırken, enerji } \\
\text { ve su tüketiminde azalma sağlanması }\end{array}$ & Ürün \\
\hline Kaizen çalışmaları & Süreç \\
\hline İleri teknoloji elyaflar & Ürün \\
\hline $\begin{array}{l}\text { Ön ve arka yüzü farklı ve pano desenlerden oluşan nevresim üretimi için nevresim otomat } \\
\text { makinasının üretilmesi }\end{array}$ & Ürün \\
\hline $\begin{array}{l}\begin{array}{l}\text { Ağır gramajlı kumaşlarda istenen en-boy-gramajı yüksek hızda sağlamak için sanfor makinasının } \\
\text { üretilmesi }\end{array} \\
\end{array}$ & Ürün \\
\hline $\begin{array}{l}\text { Dokuma bezde istenen en, çekmezlik ve homojen merserize efektini yüksek hızda sağlayan } \\
\text { merserize makinesinin üretilmesi }\end{array}$ & Ürün \\
\hline En kaliteli flanel kumaş için yeni nesil şardon makinesinin tasarımı ve prototip imalatının yapılması & Ürün \\
\hline Halat kasar makinesinde üstün kaliteli kumaş üretimi için tasarımı ve prototip imalatının yapılması & Ürün \\
\hline $\begin{array}{l}\text { Otel tekstiline yönelik ince ipliklerden yüksek sıklıkta, yüksek kaliteli yeni konstrüksiyonların } \\
\text { geliştirilmesi }\end{array}$ & Ürün \\
\hline $\begin{array}{l}\text { Kaz tüyü yastık imalatında kullanılan membran özellikli yeni kumaşlar apreli çarşafların } \\
\text { geliştirilmesi }\end{array}$ & Ürün \\
\hline $\begin{array}{l}\text { İş pantolonu-elbisesi imalatında kullanılan orta ve yüksek ağırlıklı gabardin kumaşların } \\
\text { geliştirilmesi }\end{array}$ & Ürün \\
\hline Karanlıkta gözükebilen (Glow in the dark) baskı tiplerinin geliştirilmesi & Ürün \\
\hline $\begin{array}{l}\text { Gömleklik imalatında kullanılan yaka astarları imalatında anti bakteriyel özellikli kumaşların } \\
\text { üretilmesi }\end{array}$ & Ürün \\
\hline Lyocell pamuk karışımı 40 NE iplik üretilip saten ham bezi dokunmaya başlanılması & Ürün \\
\hline 3D teknolojisi ile baskı geliştirilmesi & Ürün \\
\hline Tricolor projesi ile biyeli ve fermuarlı model geliştirilmesi & Ürün \\
\hline
\end{tabular}


Tablo 1 (Devamı): Türk Tekstil İşletmelerinin İnovasyon Uygulamaları ve İnovasyon Türleri

\begin{tabular}{|c|c|}
\hline Düz boya iki renkli otel nevresimi projesinin gerçekleştirilmesi & Ürün \\
\hline Fermuar dikişinin otomatlarda yapılabilir duruma getirilmesi & Ürün \\
\hline \multicolumn{2}{|l|}{ Şirikçioğlu Mensucat (Şirikçioğlu Mensucat, 2018) } \\
\hline İnovasyon Uygulamaları & İnovasyon Türü \\
\hline Flat Finish yıkama makinesi sayesinde karlılık optimum düzeye çıkarılması & Ürün \\
\hline \multicolumn{2}{|l|}{ Mem Tekstil (Memtextile, 2018) } \\
\hline İnovasyon Uygulamaları & İnovasyon Türü \\
\hline $\begin{array}{l}\text { AEROpiecing teknolojisine sahip tam otomatik open end iplik makinaları ile ComfoRo adı verilen } \\
\text { hemen hemen hatasız open end iplik üretilmesi }\end{array}$ & Ürün \\
\hline \multicolumn{2}{|l|}{ Yeşim Tekstil (Yeşim Tekstil, 2018) } \\
\hline İnovasyon Uygulamalar1 & İnovasyon Türü \\
\hline $\begin{array}{l}\text { Nano teknoloji harikası akıllı kumaşlar yanmayan, su tutmayan, ütü gerektirmeyen, terletmeyen } \\
\text { akıllı kumaşların Türkiye'deki ilk üreticilerinden olması }\end{array}$ & Ürün \\
\hline Birçok özelliği bir arada bulunduran "Hybrid” teknik tekstil kumaşlarının üretilmesi & Ürün \\
\hline $\begin{array}{l}\text { Organik pamuk, bambu ve soyadan elde edilen iplikle "Sustainable Textile Certificate" sertifikalı } \\
\text { kumaş üretimi }\end{array}$ & Ürün \\
\hline Yeşim Recycle adıyla maksimum \% 50 oranında geri dönüşümlü iplik üretimi & Ürün \\
\hline $\begin{array}{l}\text { Aynı müşteri gurubuna hizmet eden müşteri temsilcileri ile iletişim artırırlarak, hız kazanmayı ve } \\
\text { hatayı minimize etmeyi hedefleyen Business Unit'lerin kurulması }\end{array}$ & Pazarlama \\
\hline Tekstil sektöründe yaşanan krize karşı yalın üretim yaparak kaizenlerin geliştirilmesi & Süreç \\
\hline Müşteriye özel koleksiyon ve iç müşteriye hizmette farklılık gerçekleştirilmesi & Pazarlama \\
\hline Organik, sürdürülebilir, geri dönüşümlü, ekolojik ve biyolojik olarak parçalanabilir kumaşların & Ürün \\
\hline $\begin{array}{l}\text { Rejenere selüloz iplikler (modal, mikro modal, viskon, tensel, bambu, lenpur) Compact \& Siro } \\
\text { bükümlü ipliklerle üretilen kumaşlar }\end{array}$ & Ürün \\
\hline $\begin{array}{l}\text { Yeni nesil hibrid (anti-bakteriyel, aloe-vera efektli, uv korumalı, koku nötralize edici) kumaşların } \\
\text { üretilmesi }\end{array}$ & Ürün \\
\hline $\begin{array}{l}\begin{array}{l}\text { Nem kontrolü sağlayan kumaşların (dri-release, dri-fit, dry touch ve wicking windows patentli } \\
\text { ürünler) üretilmesi }\end{array} \\
\end{array}$ & Ürün \\
\hline $\begin{array}{l}\text { Renk halı baskı hatlarıyla, sürdürülebilirlik anlayışına ve üretimine yeni bir boyut kazandıran } \\
\text { tufting halı üreticisi olarak } 76 \mathrm{dpi} \text { çözünürlükte (sonsuz renk seçeneği), fotoğraf görselliğinde } \\
\text { üretim yapabilen dünyadaki ilk ve tek üretici olması }\end{array}$ & Ürün \\
\hline $\begin{array}{l}\text { Innovatif mineral kombinasyonu ile üretilen Biocharge, fiziksel enerji ihtiyacını optimize eden ve } \\
\text { gün içinde ihtiyaç olan enerjiyle kasları yenilemek için tıbbi olarak kanıtlanmış akıllı denim üretimi }\end{array}$ & Ürün \\
\hline $\begin{array}{l}\text { Koku absorbe edici etki yaratmak, kötü bakteri ve kokuları etkisizleştirmek için mineralize } \\
\text { volkanik kül ile zenginleştirilmiş Bıware akıllı denim üretimi }\end{array}$ & Ürün \\
\hline
\end{tabular}
volkanik kül ile zenginleştirilmiş Bıware akıllı denim üretimi

Dinarsu İmalat ve Ticaret (Sustainnovation, 2018); (Dinarsu, 2018)

\begin{tabular}{|l|c|}
\hline \multicolumn{1}{|c|}{ İnovasyon Uygulamaları } & İnovasyon Türü \\
\hline $\begin{array}{l}\text { Pet şişelerin mekanik kırılmasından elde edilen kırıkları PES elyafına dönüştürerek elde edilen } \\
\text { ipliklerden dokunmuş olan kumaş üretimi }\end{array}$ & Ürün \\
\hline
\end{tabular}

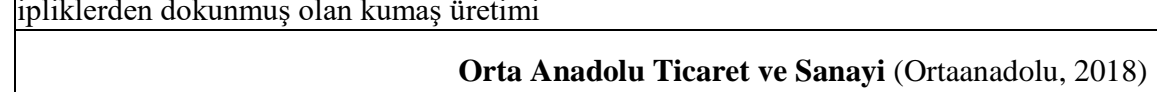

\begin{tabular}{|l|c|}
\hline \multicolumn{1}{|c|}{ İnovasyon Uygulamaları } & İnovasyon Türü \\
\hline Tasarım odaklı metropol kadının beklenti ve ihtiyaçlarından doğan Random marka ve mağaza & Pazarlama \\
\hline 2 yıl gül kokusu garantili seccade ve cami halısı & Ürün \\
\hline
\end{tabular}

Akbaşlar Tekstil (Akbaşlar Tekstil, 2018)

İnovasyon Uygulamaları

Alev almayan, kolay temizlenen, 1sı yalıtımı yapan, statik elektriklenmeyi önleyen halılar üretme İnovasyon Türü Ürün

Türkiye'nin ilk ve tek mobil perde servisi "alo perde" nin müşterilerin hizmetine sunulması Pazarlama 
Tablo 1 (Devamı): Türk Tekstil İşletmelerinin İnovasyon Uygulamaları ve İnovasyon Türleri

\begin{tabular}{|c|c|}
\hline \multicolumn{2}{|c|}{ Gürteks İplik (Gürteks, 2018); (Halıcılarodası, 2018) } \\
\hline İnovasyon Uygulamaları & İnovasyon Türü \\
\hline Türkiye'de ilk kez non-iron özellikli “Ütü Sevmez Perde” üretildi & Ürün \\
\hline Dikiş süresini en aza indirecek olan "Perde Sihirbazı" nın üretilmesi & Ürün \\
\hline
\end{tabular}

Baydemirler Tekstil (Baydemirler, 2018); (Hürriyet, 2018)

\begin{tabular}{|l|c|}
\hline \multicolumn{1}{|c|}{ İnovasyon Uygulamaları } & İnovasyon Türü \\
\hline Toz ve leke tutmaz, kaydırmaz tabanlı, tüy çıkarmaz, antialerjik, antibakteriyel ürünlerin üretilmesi & Ürün \\
\hline Re-Set kapsül koleksiyonu geliştirilerek \%100 çevreci olan Turquality sertifikası & Ürün \\
\hline Kent, sokak, motosiklet giyimi ve aktif giyim modası için geliştirilen Dyneema`nın üretilmesi & Ürün \\
\hline Ultra hafif olan, çelikten 15 kat daha güçlü Dreamy Denım üretilmesi & Ürün \\
\hline
\end{tabular}

Bossa Ticaret ve Sanayi İşletmeleri (Bossa, 2018)

İnovasyon Uygulamaları $\quad$ İnovasyon Türü

\begin{tabular}{l|l|}
\hline $\begin{array}{l}\text { Kaşmirden daha ince, ipekten daha pürüzsüz ve yünden daha sıcak olan, inovatif Japon "Miyabi” } \\
\text { lifleriyle dokunan yeni bir konfor ürününün üretilmesi }\end{array}$ & Ürün \\
\hline
\end{tabular}

Reemain (Kaynak ve Enerji Verimli Üretim) organizasyon yeniliği adına Türkiye'de uygulayan ilk ve tek proje olması

Kozmetik özelliklere sahip (antibakteriyel özellikli, serin ve zinde tutan, gül kokusu, mentol kokusu, temizlik kokusu yayan, cildin vitamin ve nem oranını artıran, aynı zamanda düzenli kullanım ile zayıflatan ve hoş tutumlara sahip) mikro teknolojili kumaşların üretilmesi

Küfü ve bakterilerin neden olduğu kokuları engelleyen, insan sağlığına zararsız ve minimum kaynak-enerji tüketilerek üretilen havlu

Kalıcı yumuşaklık etkisini \%100 doğal, sürdürülebilir, ürünün karbon ayak izini azaltan çarşaflık kumaşların üretilmesi

\begin{tabular}{|c|c|}
\hline $\mathrm{k}$ & Organizasyonel \\
\hline $\mathrm{m}$ & Ürün \\
\hline $\mathrm{m}$ & Ürün \\
\hline $\mathrm{k}$ & Ürün \\
\hline
\end{tabular}

Gamateks Tekstil (Gamateks, 2018); (Tekstil teknik, 2018)

\begin{tabular}{|c|c|}
\hline \begin{tabular}{|l|l|} 
İnovasyon Uygulamaları \\
\end{tabular} & İnovasyon Türü \\
\hline $\begin{array}{l}\text { Ani sıcaklık değişimlerine karşı koruyan nefes alabilen yıkama ile kaybolmayan kış içlikleri ve } \\
\text { bebek ürünleri }\end{array}$ & Ürün \\
\hline Sporcular için teri kumaşta en uygun biçimde yönlendiren ve yıkama ömrü uzun kumaş & Ürün \\
\hline $\begin{array}{l}\text { Outdoor spor yapanlara yönelik soğuğa karşı dirençli ve aynı zamanda nefes alabilen, çok hafif ve } \\
\text { yumuşak, fonksiyonları yıkama ile kaybolmayan kış takımı }\end{array}$ & Ürün \\
\hline $\begin{array}{l}\text { Çevreci boyahane ile kaynak ve enerji tasarrufu, kimyasal madde kullanımında, çöp ve zararlı } \\
\text { madde salımlarında azalmalar, geri dönüşüme katkıda artışlar gibi faydaların sağlanması }\end{array}$ & Süreç \\
\hline $\begin{array}{l}\text { Prospin adlı uygulama sistemi, ipliğin düzgünlüğünü, üzerindeki tüylenmeyi azaltması, daha } \\
\text { randımanlı çalışmasını ve tozlanma azalttığı için homojen bir boya emişini sağlaması }\end{array}$ & Ürün \\
\hline Açık hücreli visko teknolojisi "polimer yay teknolojisi”" & Ürün \\
\hline $\begin{array}{l}\text { Tüm yataklarda kullanılan lisanslı “Quallofil Allerban” teknolojisi yatakların lavanta kokmasını } \\
\text { sağlaması }\end{array}$ & Ürün \\
\hline \multicolumn{2}{|l|}{ Özdilek Ev Tekstil (Özdilek, 2018); (İstekkobi, 2018) } \\
\hline İnovasyon Uygulamaları & İnovasyon Türü \\
\hline Anti-stress etkisine sahip özel "nano teknoloji” ile üretilmiş yatak & Ürün \\
\hline \multicolumn{2}{|l|}{ İşbir Sentetik Dokuma (İşbirbigbag, 2018); (İşbir yatak, 2018); (Acarpatent, 2018) } \\
\hline İnovasyon Uygulamaları & İnovasyon Türü \\
\hline Atsaçı yatak & Ürün \\
\hline Hindistan cevizi özlü yatak & Ürün \\
\hline Sporcular için özel nem tutmayan yatak & Ürün \\
\hline $\begin{array}{l}\text { Karbon iplikler barındıran, vücutta biriken statik elektriği nötr hale getiren v } \\
\text { azaltılmasına katkıda bulunan yatak üretilmesi }\end{array}$ & Ürün \\
\hline
\end{tabular}


Tablo 1 (Devamı): Türk Tekstil İşletmelerinin İnovasyon Uygulamaları ve İnovasyon Türleri

\begin{tabular}{|l|c|}
\hline Yurtiçinde “İşbir Yatak Uyku Merkezi” konsept mağaza & Pazarlama \\
\hline Yurtdışında ise "Life Sleep Center” konsept mağaza & Pazarlama \\
\hline Viskoelastik ile programlanabilir kumandalı ve titreşimli masaj sistemiyle Viscostar Nature & Ürün \\
\hline Strese karşı ve deniz yosunu özleriyle cildi besleyen Seacell Wellness Anti Stress yatakların & Ürün \\
\hline
\end{tabular}

Gerçekleştirilen inovasyonların, inovasyon çeşitlerine göre dağılımı Tablo 2'de verilmektedir.

Tablo 2: Tekstil İşletmelerinin İnovasyon Türlerinin Dağılımı

\begin{tabular}{|l|c|c|}
\hline İnovasyon Türü & İnovasyon Adet & $\mathbf{\%}$ \\
\hline Ürün & 84 & 87,50 \\
\hline Pazarlama & 7 & 7,29 \\
\hline Süreç & 4 & 4,17 \\
\hline Organizasyonel & 1 & 1,04 \\
\hline Toplam & 96 & 100,00 \\
\hline
\end{tabular}

Tablo 2'ye göre tekstil işletmeleri \%87,50'lik bir payla en fazla ürün inovasyonu gerçekleştirmişlerdir. Ürün inovasyonunu \%7,29'la pazarlama, \%4,17'le süreç ve \%1,04'le organizasyonel inovasyon izlemektedir.

Tekstil işletmelerinin en fazla gerçekleştirdikleri inovasyon türü olan ürün inovasyonları incelendiğinde, işletmelerin en fazla kumaş geliştirmek için inovasyon uygulamalarına başvurdukları görülmektedir. Kumaştan sonra ise makine ve teknoloji geliştirmek için inovasyon uygulamaları yaptıkları sonucuna ulaşılmıştır. Makine inovasyonlarına; Dijital Baskı, Renkli Baskı, Dokuma, Desen, Sanfor, Merserizasyon, Şardonlama, Halat Kasar, Tam Otomatik Open End İplik, Yıkama, Fermuar Otomatı gibi makineler örnek verilebilir. Diğer yandan geliştirilen teknolojilere ise; 3D Baskı, Kumaş Geri Kazanım, Apraj Problemini Çözme, Torba Üretimi, Yüzey kalitesini iyileştirme, kürlenme süresini Kısaltma, Enerji Tasarrufu, Dikiş Süresini Kısaltma, Tricolor Model Geliştirme teknolojileri örnek verilebilir. Ayrıca Halı, İplik, Lif ve Giysi alanlarında da az da olsa ürün inovasyonlarına rastlamak mümkündür.

Tekstil işletmelerinin ürün inovasyonundan sonra en fazla gerçekleştirdikleri inovasyon türü pazarlama inovasyonudur. İşletmeler tarafından gerçekleştirilen pazarlama inovasyonları incelendiğinde ise; Kişiye Özel Ürün Üretimi, Mağaza Konsepti, Müşteriyle İlişkiler, Mobil Pazarlama ve Moda Akımı Oluşturma gibi inovasyonlar tespit edilmiştir.

Tekstil işletmelerinin en fazla gerçekleştirdikleri üçüncü inovasyon olan süreç inovasyonları incelendiğinde ise; yalın üretim, üretim hızının artırılması ve geri dönüşüm temelli inovasyonlar tespit edilmiştir.

Tekstil işletmelerinin en az gerçekleştirdikleri inovasyon türü ise organizasyonel inovasyondur. $\mathrm{Bu}$ inovasyona ise üretimde kaynak ve enerji verimliliği konusu örnek verilebilir.

\section{Sonuç ve Öneriler}

Günümüz hızlı rekabet ortamında inovasyon tüm işletmeler için olmazsa olmaz unsurlardan biri olarak görülmektedir. Özellikle 4. Sanayi Devrimi (Endüstri 4.0)'nin konuşulduğu 
bugünlerde işletmelerin gerçekleştirdikleri inovasyonlar daha da önemli bir hal almıştır (Yılmaz Aykul, 2018). Bu bağlamda Türk tekstil işletmeleri tarafindan gerçekleştirilen inovasyon uygulamaları İSO'nun birinci ve ikinci 500 büyük işletme sıralamasına girmiş tekstil işletmeleri üzerinden incelenmiştir. İlgili işletmeler Türkiye'nin en büyük tekstil işletmeleri olmaları açısından önemlidir. Ayrıca bu işletmeler sektöre yön veren ve diğer işletmeler tarafından örnek alınan işletmelerdir. Dolayısıyla bu işletmelerin durumu sektörün ve Türkiye`nin geleceği açısından önemli olmaktadır. Tekstil işletmelerinin imalat sanayi istihdamı ve ihracatında önemli konuma sahip olması, bu işletmelerdeki tüm gelişmelerin Türkiye ekonomisine olumlu/olumsuz etki etmesine neden olmaktadır. Bu nedenle tekstil sektötünde inovasyon faaliyetleri büyük önem arz etmektedir (Terzioğlu vd., 2008).

Araştırma kapsamında elde edilen verilerden; incelenen 40 tekstil işletmesinin \%50'sinin ürün, süreç, pazarlama ve organizasyonel inovasyon türlerinden en az birinde inovasyon faaliyeti gerçekleştirmeyi başarmış olmaları olumlu olarak değerlendirilirken, geri kalan \%50'lik kısmı oluşturan işletmelerde herhangi bir inovasyon faaliyetinin olmaması sektörün geleceği açısından parlak bir duruma işaret etmemektedir. Ayrıca Türk tekstil sektörünün inovasyon açısından durumunu tespit etmek amaciyla, sektörün en önde gelen işletmelerinden veri elde edilerek yapılan araştırma sonucunda bile sektörün inovasyon açısından durumun iyi olmadığını göstermesi, örneklem grubunun genişletilmesi durumunda daha da olumsuz bir sonuç elde edileceği anlamına gelmektedir.

Araştırma sonucunda Türk tekstil işletmelerinin toplam 96 adet inovasyon faaliyeti gerçekleştirdikleri tespit edilmiştir. En fazla inovasyon gerçekleştiren işletme 18 adet inovasyon gerçekleştirirken en az inovasyon gerçekleştiren işletme 1 adet inovasyon gerçekleştirmeyi başarmıştır. Türk tekstil işletmeleri ortalama 4,95 adet inovasyon gerçekleştirmeyi başarmışlardır. Gerçekleştirilen inovasyonların \%87,8'lik kısmı (87 adet) ürün inovasyonlarıdır. Ürün inovasyonunu \%6,06'la (6 adet) pazarlama ve \%3,03’le (3 adet) süreç inovasyonu izlemektedir. Bu durum işletmelerin öncelikli olarak ürün inovasyonuna yöneldiğini göstermektedir. Ancak işletmelerin amaçlarının sadece üretim olmadığı, üretim sürecinin iyileştirilmesi, verimli organizasyonların gerçekleştirilmesi ve üründen maksimum karın sağlanması için pazarlama süreçlerinin çok iyi planlanması da gerekmektedir. Bu açıdan düşünüldüğünde tekstil işletmelerinin diğer inovasyon (pazarlama, süreç ve organizasyonel) türlerine de daha fazla yönelmeleri gerekmektedir. Diğer yandan inovasyonun ihracat üzerindeki pozitif etkisi düşünüldüğünde tekstil işletmelerinin yurt dışına daha fazla ürün pazarlayabilmeleri için inovatif ürünler üretmeleri gerekmektedir (Çütçü ve Çelik, 2016). Bununla birlikte tekstilde tasarım ve inovasyon arasında güçlü bir ilişki olduğu ve bu nedenle tekstildeki tasarım başarsının inovatif düşünceler ve teknolojiye bağlı olduğunu söylemek mümkündür (Yılmaz Aykul, 2018). Daha önce yapılmış araştırma sonuçlarına göre işletmelerde nitelikli çalışan sayısı arttıkça inovasyon sayısının arttığı (ürün, süreç, pazarlama ve organizasyonel) ve işletme büyüklüğü ile inovasyon eğilimi arasında doğru yönlü bir ilişkinin olduğu tespit edilmiştir. Bu bağlamda tekstil işletmelerinin nitelikli çalışan sayılarını ve organizasyon büyüklüklerini dengeli bir şekilde artırmaları önerilmektedir. Ayrıca aşırı büyüme örgütlerde hantallığa neden olarak esnekliği azaltacağı ve böylece inovasyon yeteneğini olumsuz etkikleyeceğinden önerilmemektedir ( Çetin ve Gedik, 2017; Kalay ve Kizildere, 2015).

Sonuç olarak tekstil işletmelerinin en fazla gerçekleştirmiş olduğu inovasyon türü ürün inovasyonudur. Bu durum inovatif ürünlerin üretimine neden olarak daha sonra bu ürünlerden maksimum karı elde etme isteğini tetikleyeceğinden pazarlama sorununu da beraberinde getirecektir. Bu sorunun çözmek için işletmelerin, önce pazarlama ve daha sonra diğer (süreç ve organizasyonel) inovasyon faaliyetlerini artırmaları gerekmektedir. Özdevecioğlu ve Biçkes 
(2012) araştırmalarında örgütsel öğrenme ile inovasyon arasında pozitif yönlü bir ilişkinin olduğu sonucuna ulaşmışlardır. Bu bağlamda sanayi ve ticaret odaları ile üniversitelerin birlikte gerçekleştireceği faaliyetlerle Türk tekstil işletme örgütlerine, inovasyonun önemi ve inovasyonu geliştirme faaliyetleri kapsamında eğitim vermeleri bu örgütlerin inovasyon faaliyetlerine olan ilgilerini artırabileceği düşünülmektedir. Ayrıca üniversitelerin tekstil bölümlerinde inovasyon derslerinin konulması gelecekte Türk tekstil sektörünün inovasyon sorununun çözümüne katkı sağlayabileceği söylenebilmektedir. Bu çalışmada elde edilen verilerin kaynağının işletme yöneticileriyle gerçekleştirilen e-posta ve telefon görüşmeleri ile işletmelerin resmi web sitelerine dayanması bu araştırmanın kısııııı oluşturmaktadır. Bundan sonraki çalı̧̧alarda, daha geniş bir örneklem üzerinde anket ve mülakat tekniklerinin birlikte kullanılarak başka ülkelerle karşılaştırmalı bir araştırmanın yapılması önerilmektedir. Diğer yandan bu araştırmanın tekstil sektörü temsilcilerine ve yöneticilerine inovasyon yönetimi konusunda yol gösterici olacağı düşünülmektedir.

\section{Kaynakça}

Acarpatent (2018). https://acarpatent.wordpress.com/tag/inovasyon-2/, (Erişim: 15.08.2018).

Akbaşlar Tekstil (2018). http://www.akbaslartekstil.com/faaliyetler/konfeksiyon, (Erişim: 10.08.2018)

Alan, M. A. (2018). İmalat Sanayiinde Teknoloji Transferi, İnovasyon, İhracat ve Firma Performansı İlişkilerinin İncelenmesi: Türkiye'deki İhracatçı Firmalarda Bir Uygulama, Yüksek Lisans Tezi, Ağrı İbrahim Çeçen Üniversitesi Sosyal Bilimler Enstitüsü, Ağrı.

Altuntaş, S., \& Dereli, T. (2016). "Savunma Sanayiinde Teknoloji Gelişimi Mühimmat ve Tahrip Teknolojileri Üzerine Bir Uygulama", Girişimcilik ve İnovasyon Yönetimi Dergisi, 5(2), 105-123.

Akın, Ö., \& Reyhanoğlu, M. (2014). İşletme Büyüklükleri Bağlamında Türkiye'nin İnovasyon Portresi (2002-2008 Dönemi), Dokuz Eylül Üniversitesi Sosyal Bilimler Enstitüsü Dergisi, 6 (1), 23-51.

Barburski, M., Pieklak, K., \& Masajtis, J. (2016). Innovative Technical Textiles. Lodz: Lodz University of Technology.

Baydemirler (2018). http://www.baydemirler.com.tr/brillant-store/, (Erişim: 12.08.2018).

Bayhan, B. D. (2004). Teknoloji ve İnovasyon Yönetimi. Ankara: TMMOB 50. Y1l Yayınları.

Berkalp, Ö. B. (2008). "Teknik Tekstiller", https://web.itu.edu.tr/ berkalpo/Teknik_Tekstil_Siniflandirmasi.pdf, (Erişim: 20.01.2019).

Bossa (2018). http://www.bossa.com.tr/denimtag\#ASPIRED, (Erişim: 13.08.2018).

Boyteks (2018). http://www.boyteks.com/mattress-ticking/innovation/quantech-sleep/, (Erişim: 05.08.2018).

Choi, W., Powell, N. B., \& Cassill, N. L. (2005). "New Product Development and Its Applications in Textiles", Article Designation: Scholarly, 4(4), 1-28.

Coşkun, E., \& Oğulata, R. T. (2008). "Akıllı Tekstiller ve Genel Özellikleri", Ç.Ü Fen Bilimleri Enstitüsü, 18(3), 100-109. 
Çakın, E., \& Özdemir, A. (2018). “KOBİ’lerde İnovasyon Performansını Etkileyen Faktörlerin Bulanık DEMATEL Tabanlı Analitik Ağ Süreci (BDANP) Yöntemiyle Analizi ve Bir Uygulama”, Dokuz Eylül Üniversitesi Sosyal Bilimler Enstitüsü Dergisi, 20(4), 559-586.

Çetin, K., \& Gedik, H. (2017). “İşletmelerde İnovasyona Etki Eden Faktörler: Karaman İli Örneği”, Uluslararası Yönetim İktisat ve İşletme Dergisi, 13(5), 160-172.

Çütçü, İ., \& Çelik, M. (2016). "İnovasyonun Tekstil İhracatına Etkisi: Güneydoğu Anadolu Bölgesi Uygulaması”, Gazi Üniversitesi Sosyal Bilimler Dergisi, 3(5), 15-42.

Çütcü, İ. (2017). "İnovasyonun İhracat Performansına Etkisi: Yatay-Kesit Analizi Uygulamasi", Journal of International Social Research, 10(48), 586-596.

Dinarsu (2018).www.dinarsuhali.com.tr, (Erişim: 09.08.2018).

Dornier, P. D. (2015). "Technologies Powering Textile Innovation", https://www.itma.com/docs/default-source/downloads/nwttbrochure/itma_nwtt_bro.pdf?sfvrsn=2, (Erişim: 13.01.2019).

Elçi, Ş., \& Karataylı, İ. (2008). İnovasyon Rehberi: Kârlılık ve Rekabetin Elkitabı. Ankara: Technopolis Group Türkiye.

Gamateks. (2018). http://www.gamateks.com.tr, (Erişim: 15.08.2018).

Gkypali, A., Rafailidis, A., \& Tsekouras, K. (2015). "Innovation and Export Performance: Do Young and Mature Innovative Firms Differ?", Eurasian Business Review, 5(2), 397-415.

Gonzales, R., Llopis, J., \& Gasco, J. (2013). "Innovationin Public Services: Tha Case of Spanish Local Governtment”, Journal of Business Research, 66(10), 2024-2033.

Gülcan, Y., Akgungor, S., \& Kustepeli, Y. (2011). "Knowledge Generation and Innovativeness in Turkish Textile Industry: Comparison of Istanbul and Denizli", European Planning Studies, 19(7), 1129-1243. Doi:10.1080/09654313.2011.573134

Gülsan Holding. (2018). http://www.gulsanholding.com/ilklerimiz, (Erişim: 03.08.2018).

Gürcüm, B.H ve Bulat, F. (2016). Tekstil Tasarımında İnovatif Bir Yaratıcılık Aracı Olarak Lazer Kesim. İdil Sanat ve Dil Dergisi, 6 (28), 107-130.

Gürteks. (2018). www.gurteks.com.tr (Erişim: 10.08.2018).

Haber7 (2018). http://www.haber7.com/gaziantep/2461839-dunyaca-unlu-kot-markalarininkumaslari-iskodan, (Erişim: 02.08.2018).

Haberalanya (2018). http://www.haberalanya.com.tr/ekonomi/enerji-verimliliginde-birincilikodulu-merinos-un-h485.html, (Erişim: 03.08.2018).

Haberler (2018). https://www.haberler.com/gaziantep-te-bolgesel-inovasyon-gunleri8286816-haberi/, (Erişim: 02.08.2018).

Habikoğlu, E. H. (2015). "İnovasyon Ekonomisi Bağlamında İnovasyon Türleri ve İnovasyon", İktisadi Araştırmalar Vakfi, 40-46.

Halıcılarodası. (2018). http://www.halicilarodasi.com/anasayfa_detay.asp?id=615, (Erişim: 11.08.2018).

Herstad, S. J. (2018). "Product Innovation and Employment Growth at The Firm Level: A Quantile Regression Approach To Inter-Industry Differences", Applied Economics Letters, 25(15), 1062-1065. Doi:10.1080/13504851.2017.1394970 
Hürriyet (2018). http://www.hurriyet.com.tr/ekonomi/2-yil-gul-kokan-seccade-uretecek25513185, (Erişim: 13.08.2018).

İlter, B., Atrek, B., \& İlayda, İ. (2016). “İnovasyon Faaliyetlerinde Kullanıcının Yeri ve Çevrimiçi Kullanıcı İnovasyon Araçları”, Yönetim ve Ekonomi: Celal Bayar Üniversitesi İktisadi ve İdari Bilimler Fakültesi Dergisi, 23(1), 35-56.

İSKO. (2018). http://www.isko.com.tr/news/, (Erişim: 03.08.2018).

İstekkobi. (2018). http://www.istekobi.com.tr/kobi-bilgi-merkezi/haberler/ozdilek-ev-tekstilive-avm-de-optimal-buyuklugu-hedefliyor-h46780.aspx, (Erişim: 15.08.2018).

İşbir yatak (2018). https://www.isbiryatak.com/basin-odasi/isbir-yataktan-inovatif-urunler-0112-2010-gastronomi/, (Erişim: 15.08.2018).

İşbirbigbag (2018). http://www.isbirbigbag.com/detay-3, (Erişim: 15.08.2018).

Işık, N., \& Kılınç, E. C. (2016). “İnovasyon-Temelli Ekonomi: Seçilmiş Ülkeler Üzerine Bir Uygulama”, Anadolu Üniversitesi Sosyal Bilimler Dergisi, 16(1), 13-28.

Jacoangeli, M. (2019). “Textil-Mode. Die Industrie Ist Flexibel und Innovativ", https://www.textil-mode.de/branche/daten-zahlen, (Erişim: 11.01.2019).

Kalay, F., \& Kızıldere, C. (2015). "Türk İşletmelerinin İnovasyon Performansını Etkileyen Faktörler Üzerine Bir Araştırma”, Ordu Üniversitesi Sosyal Bilimler Araştırmaları Dergisi, 5(13), 36-63.

Kardağlı, F. S. (2010). Tekstil Sektöründe Tasarım Yoluyla Rekabette Malzeme İnovasyonunun Rolü: Türkiye'den Örnekler, Yüksek Lisans Tezi, İstanbul Teknik Üniversitesi Fen Bilimleri Enstitüsü, İstanbul

Kaynak, S., \& Demir, A. (2015). "İmalat Sektöründe İnovasyon Uygulamaları: TRA1 Düzey 2 Bölgesinde Bir Araştırma”, Atatürk Üniversitesi Sosyal Bilimler Enstitüsü Dergisi, 19(3), 273-292.

Kılıç, R., \& Keklik, B. (2012). "KOBİ'lerde Genel Firma Özelliklerinin İnovasyon Uygulamalarına Etkisi: Balıkesir İlinde Bir Araştırma”, Erciyes Üniversitesi İktisadi ve İdari Bilimler Fakültesi Dergisi, (39), 93-118.

Kipaş Mensucat (2018). http://www.kipasmensucat.com/kurumsal/inovasyon/ar-ge.html, (Erişim: 03.08.2018).

Koçoğlu, D., Sarıtaş, E. (2016). "İhracat Pazarlama Faaliyetlerinde Pazarlama Karması Adaptasyonu ve Denizli Tekstil Sektöründe Bir Araştırma", Pamukkale Üniversitesi Sosyal Bilimler Enstitüsü Dergisi, 25(1), 124-134.

Kordsa (2018). http://www.kordsa.com/R-D-and-innovation.asp?g=1\&d=tr， (Erişim: 03.08.2018).

Kordsa (2018). http://www.kordsa.com/press_releases_alt.asp?g=1\&d=tr\&hid=370, (Erişim: 03.08.2018).

Kordsaglobal (2018). http://www.kordsaglobal.com, (Erişim: 03.08.2018).

Kuştepeli, Y., \& Gülcan, Y. (2010). "Türk Tekstil Kümelerindeki Bilgi Tabanı Farklılıklarının Ölçümü ve Yenilikçilik”, Gazi Üniversitesi İktisadi ve İdari Bilimler Fakültesi Dergisi, 12(1), 57-76. 
Küçükkalay, A. G. A. M. (1997). "Endüstri Devrimi Ve Ekonomik Sonuçlarının Analizi”, Süleyman Demirel Üniversitesi İktisadi ve İdari Bilimler Fakültesi Dergisi, 2(2), 51-68.

Küsters, D., Praß, N., \& Gloy, Y.-S. (2017). "Textile Learning Factory 4.0 - Preparing Germany's Textile Industry for the Digital Future”, Procedia Manufacturing, 9, 214-221. Doi:10.1016/j.promfg.2017.04.035

Mecit, D., Ilgaz, S., Duran, D., Başal, G., Gülümser, T., \& Tarakçığlu, I. (2007). “Teknik Tekstiller ve Kullanım Alanları (Bölüm1)”, Tekstil ve Konfeksiyon Dergisi, 17(2), 7982.

Memtextile (2018).https://docplayer.biz.tr/35362999-Mem-tekstil-sanayi-ticaret-anon-stiturkiye-deki-tam-entegre-iplik-tesisi.html, (Erişim: 08.08.2018).

Menderes (2018). http://www.menderes.com/download/files/9498783338_ , (Erişim: 06.08.2018).

Menderes Tekstil (2017). "Menderes Tekstil Faaliyet Raporu”, http://www.menderes.com/download/files/6364521942_Mndrs\%20Faaliyet\%20Raporu \%2006.17.pdf, (Erişim: 07.08.2018).

Menderes Tekstil Sanayi ve Ticaret A.Ş. (2018). Menderes Tekstil Sanayi ve Ticaret A.Ş. İstanbul: Ata Uluslararası Bağımsız Denetim ve SMMM A.Ş.

Merinos (2018). http://www.merinos.com.tr, (Erişim: 03.08.2018).

Metin, M. (2014). Kuramdan Uygulamaya Eğitimde Bilimsel Araştırma Yöntemleri, Ankara: Pegem Akademi.

OECD. (2005). Oslo Klavuzu: Yenilik Verilerinin Toplanması ve Yorumlanması İçin İlkeler. Ankara: OECD (Çeviren: TÜBITTAK).

Oğuztürk, B. S., \& Türkoğlu, M. (2004). "Yenilik ve Yenilik Modelleri”, Doğu Anadolu Bölgesi Araştırmaları, 3(1), 14-20.

Ortaanadolu (2018). http://www.ortaanadolu.com, (Erişim: 10.08.2018).

Özbek, A. (2007). “Ak1llı Giysiler”, Nonwoven Technical Textiles, (15), 70-77.

Özdevecioğlu, M., \& Biçkes, D.M. (2012). "Örgütsel Öğrenme ve İnovasyon İlişkisi: Büyük Ölçekli İşletmelerde Bir Araştırma", Erciyes Üniversitesi İktisadi ve İdari Bilimler Fakültesi Dergisi, (39), 19-45.

Özdilek (2018). http:// www.ozdilek.com.tr, (Erişim: 15.08.2018).

Padilha, C. K., \& Gomes, G. (2016). "Innovation Culture And Performance in Innovation of Products and Processes: A Study in Companies of Textile Industry”, RAI Revista de Administração e Inovação, 13(4), 285-294. Doi:10.1016/j.rai.2016.09.004

Paret, D., \& Crégo, P. (2019). Wearables, Smart Textiles and Smart Apparel. London: ISTE Press Ltd. Doi:10.1016/B978-1-78548-293-9.50010-6

Rosli, M. M., \& Sidek, S. (2013). "The Impact of Innovation on the Performance of Small and Medium Manufacturing Enterprises: Evidence from Malaysia”, Journal of Innovation Management in Small \& Medium Enterprise, 2013, 1-16. Doi:10.5171/2013.885666

Sanko Tekstil İşletmeleri (2018). http://www.sanko.com.tr, (Erişim: 02.08.2018). 
Savaş, H. (2015). Ürün İnovasyonunu Etkileyen Faktörler Üzerine Bir Literatür Taraması. In ISITES2015 3rd International Symposium on Innovative Technologies in Engineering And Science, Valencia -Spain, 2327-2337.

Sustainnovation (2012). http://sustainnovation.net/zimmerin-proses-renk-hali-baskisi-devrimisurdurulebilir-uretimin-onunu-acti/, (Erişim: 10. 08.2018).

Şaylan, O., \& Esmer, Y. (2017). "Endüstriyel İşletmelerin Yeni Ürün Geliştirme Sürecinde Müşteri Katılımına Yönelik Teorik Bir Araştırma”, IBANESS Konferans Serisi, (s. 437442). Kirklareli.

Şencan, H., Çemberci, M., Bayraktar, O., Arslan, K., Uca, N., (2015). Tekstil Sektörü 2023 Stratejileri, İstanbul Ticaret Odası Yayınları No: 2015-7, İstanbul.

Şendoğdu, A. A., \& Öztürk, Y. E. (2013). "KOBİ'lerde İnovasyon Yapma Eğilimi İle İnovasyon Performans Başarı Derecesi Arasındaki İlişkinin Araştırılması", Ömer Halisdemir Üniversitesi İktisadi ve İdari Bilimler Fakültesi Dergisi, 6(2), 104-116.

Şirikçioğlu Mensucat (2018). http://www.sirikcioglu.com.tr/kurumsal-gelisim.aspx?2006, (Erişim: 08.08.2018).

Taylan, M., Atlıhan, Ş., (2018). Tekstil Tasarımında Doğal Elyaf ve Doğal Boya Kullanımı, İdil, 7 (43), 319-326.

Tekstil Teknik (2018). http://www.tekstilteknik.com.tr/gamateks-inovatif-projelerle-dikkatcekiyor/, (Erişim: 15.08.2018).

Terzioğlu, M., Avcı, M., \& Gökovalı, U. (2008). "İşletmelerde Yenilik Yeteneği: Denizli Tekstil Ve Hazır Giyim Sektörü Örneği”, Çukurova Üniversitesi Sosyal Bilimler Enstitüsü Dergisi, 17(3), 377-388.

Texotex (2018). http://www.textotex.com/haber/terbiye/monfortstan-kipasa-odul.html, (Erişim: 03.08.2018).

TiD (2014). Haberler, Tekstil İşveren Dergisi, 405, 1-8.

Wadho, W., \& Chaudhry, A. (2018). "Innovation and Firm Performance in Developing Countries: The Case of Pakistani Textile and Apparel Manufacturers”, Research Policy, 47(7), 1283-1294. Doi:10.1016/j.respol.2018.04.007

Yazıcı, S. (2018). “Inovasyon, Rekabet ve Devlet”, Turkish Studies: Information Technologies \& Applied Sciences, 13(13), 67-86. Doi:10.7827/TurkishStudies.13388

Yeşil, S., Çınar, Ö., \& Uzun, E. (2010). "Kahramanmaraş’ta Faaliyet Gösteren İşletmelerin Yenilik Faaliyetleri Üzerine Bir Alan Çalışması”, Bilgi Ekonomisi ve Yönetimi Dergisi, 5(2), 81-100.

Yeşim Tekstil (2018). http://www.yesim.com/icerik/22/inovatif-uygulamalar/, (Erişim: 10.08.2018).

Yeşim Tekstil. (2018). http://www.yesim.com/icerik/23/ar-ge/, (Erişim: 10.08.2018).

Yılmaz Aykul, S. (2018). “Tekstil Tasarımındaki İnovatif Düşünceler”, Göller Bölgesi Aylık Hakemli Ekonomi ve Kültür Dergisi Ayrınt1, 5(62), 47-51.

Yorgancılar, F. N. (2011). "Sürdürülebilir Rekabet Anlayışı Olarak Yenilik Yeteneği”, SÜ İİBF Sosyal ve Ekonomik Araştırmalar Dergisi, 11(21), 379-426.

Zorlu Tekstil (2018). http://www.zorlutekstil.com.tr, (Erişim: 04.08.2018). 


\section{EXTENDED ABSTRACT}

\section{A Research of Innovation Applications in Textile Enterprises: The Case of Istanbul Chamber of Industry}

In today's global competition conditions, innovation is one of the most important tools that textile enterprises can use to reach and maintain a competitive position. Especially in the days when Industry 4.0 was discussed, the innovations realized by textile enterprises became even more important. In this context, the innovation practices carried out by the Turkish textile enterprises are examined through the textile enterprises which have succeeded to rank in the first and second 500 largest enterprises of Istanbul Chamber of Industry (ISO). As a result of the research, it is considered that $50 \%$ of the 40 textile enterprises have succeeded in carrying out innovation activities in at least one of the product, process, marketing and organizational innovation types. However, the absence of any innovation activity in other textile enterprises does not indicate a bright situation for the future of the sector. In addition, it was determined that Turkish textile enterprises carried out a total of 96 innovation activities. The highest number of innovations has been achieved by 18 innovations, while the least by one innovation. Turkish textile enterprises managed to realize an average of 4.95 innovations. $87.8 \%$ of the innovations realized (87) are product innovations. Product innovation is followed by marketing with $6.06 \%$ (6) and process innovation with $3.03 \%$ (3). This situation shows that enterprises are primarily oriented towards product innovation. However, it is also necessary to plan the marketing processes very well in order to improve the production process, to realize productive organizations and to obtain maximum profit from the product. From this point of view, textile enterprises need to focus more on other types of innovation (marketing, process and organizational). On the other hand, considering the positive effect of innovation on exports, textile enterprises are required to produce innovative products in order to market more products abroad (Cutcu and Celik, 2016). However, it is possible to say that there is a strong relationship between design and innovation in textile and therefore the success of design in textile depends on innovative ideas and technology (Y1lmaz Aykul, 2018). According to the results of the previous research, as the number of qualified employees increases in the enterprises, the number of innovations increases (product, process, marketing and organizational) and it is found that there is a direct relationship between the size of the enterprise and the tendency of innovation. In this context, it is recommended that textile enterprises increase the number of qualified employees and organization size in a balanced way. In addition, over-growth is not recommended as it will reduce flexibility by causing bulkyness in organizations and thus adversely affect innovation ability (Cetin and Gedik, 2017; Kalay \& Kizildere, 2015).

As a result, the most common type of innovation realized by textile enterprises is product innovation. This will lead to the production of innovative products, which in turn triggers the desire to generate maximum profit from these products, which in turn leads to the marketing problem. To solve this problem, enterprises need to increase marketing and then other (process and organizational) innovation activities. Ozdevecioglu and Bickes (2012) concluded that there is a positive relationship between organizational learning and innovation. In this context, it is thought that these organizations may increase their interest in innovation activities by providing trainings to Turkish textile business organizations through the activities to be realized jointly by chambers of industry and commerce and universities within the scope of the importance of innovation and innovation development activities. Furthermore, it can be said that the introduction of innovation courses in the textile departments of universities may contribute to the solution of the innovation problem of the Turkish textile sector in the future. The limitation of this research is that the data obtained in this study is based on e-mail and telephone interviews with business executives and the official websites of the enterprises. In the following studies, a comparative study with other countries is suggested using a combination of survey and interview techniques on a larger sample. On the other hand, this research is expected to guide textile sector representatives and managers on innovation management. 